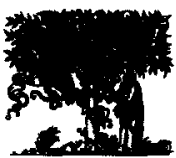

ELSEVIER

\title{
Further studies on the controlled atmosphere storage of avocados
}

\author{
Shimon Meir ${ }^{*}$, Miriam Akerman, Yoram Fuchs, Giora Zauberman \\ ARO, Institute for Technology and Storage of Agricultural Products, Department of Postharvest Science of \\ Fresh Produce, The Volcani Center, P.O. Box 6, Bet Dagan 50250, Israel
}

Accepted 27 July 1994

\begin{abstract}
The effects of controlled atmospheres (CA) of six different compositions, on the keeping quality of stored 'Hass' avocado fruit were studied. Atmospheres containing 1, 3 and $8 \%$ carbon dioxide in combination with $21 \%$ oxygen and atmospheres containing $0.5,3$ and $8 \%$ carbon dioxide in combination with $3 \%$ oxygen were tested. Storage temperature was $5^{\circ} \mathrm{C}$ and shelf-life (ripening) temperature was $20^{\circ} \mathrm{C}$ for all treatments. Results show that elevated carbon dioxide and reduced oxygen concentrations in the atmosphere retarded ripening (softening and peel colour changes), and reduced the development of chilling injuries during storage at $5^{\circ} \mathrm{C}$. The $8 \%$ carbon dioxide concentration was more effective than $3 \%$, in combination with either oxygen concentration. An atmosphere containing $3 \%$ oxygen and $8 \%$ carbon dioxide was the best with respect to the parameters mentioned above, and made 9 weeks of avocado storage possible. These results indicate that the two gases have a synergistic effect on inhibiting ripening processes. Following CA storage, fruits softened normally and the peel went through the usual, typical colour changes. However, these two ripening processes were not always in step, suggesting that CA may have a differential effect on ripening of avocado peel and pulp.
\end{abstract}

Keywords: Avocado; Controlled atmosphere; Chilling injury; Prolonged storage

\section{Introduction}

It has been shown that by combining controlled atmosphere (CA) with lowtemperature storage, it is possible to delay fruit ripening and prolong its storage durability (Smock, 1979; Wang, 1990). CA technology is used commercially for deciduous fruits such as apples, pears, persimmons, kiwi, plums and pomegranates (Smock, 1979; Blanpied, 1990). Atmospheres containing low concentrations of

* Corresponding author. Fax: 97239683622. 
oxygen have also been reported to reduce chilling injuries in some of the above fruit species, possibly by inhibition of the accelerated oxidation processes associated with some chilling injuries (Bramlage and Meir, 1990; Wang, 1990). Chilling injury in avocado fruit is characterized by flesh discolouration in the early stages of development, with the pulp (mesocarp) becoming dark brown in later stages (Chaplin et al., 1982). This discolouration in avocado has been attributed to oxidation of phenols by polyphenol oxidase (Kahn, 1975; Golan et al., 1977; Bower et al., 1990; Truter et al., 1991, 1992). Some successful studies using CA storage in avocado with fruit of the 'Lula', 'Waldin', 'Fuchs', 'Fuerte' and 'Hass' cultivars, have been reported to prevent chilling injury (Young et al., 1962; Hatton and Reeder, 1972; Spalding and Reeder, 1975; Barmore and Rouse, 1976; Arpaia et al., 1990; Hatton and Spalding, 1990; Truter et al., 1991; Faubion et al., 1992). In these studies, a successful prolonged storage of 5-9 weeks duration was obtained between 5 and $7^{\circ} \mathrm{C}$, and the best results obtained at an atmosphere of $2 \%$ oxygen and $10 \%$ carbon dioxide. Additional successful CA storage studies with 'Hass' and 'Reid' cultivars at temperatures of 5 and $4^{\circ} \mathrm{C}$, respectively, have been performed (Resnizky and Sive, 1989), but the gas concentrations employed were not reported.

In the present study, the effects on the keeping quality of 'Hass' avocado fruit (grown in the coastal plain of Israel) of several combinations of oxygen and carbon dioxide concentrations, were tested at $5^{\circ} \mathrm{C}$.

\section{Materials and methods}

'Hass' avocado (Persea americana Mill.) fruit (150-200 g each, and containing, on the average, 30.5\% dry matter) was harvested on March 20, 1992 at kibbutz Na'an. After 2 days storage at $5^{\circ} \mathrm{C}$, the unwaxed fruit was dipped in $0.2 \%$ "Prochloraz" ( $N$-propyl- $N$-[2-(2,4,6-trichlorophenoxy) ethyl] imidazole-1-carboxamide) solution, dried at about $20^{\circ} \mathrm{C}$ for 30 min and subsequently placed, 90-95 fruits, in each 30-1 plastic containers. The CA in the containers was maintained by means of a gas flow system of air, carbon dioxide and nitrogen, at a flow rate of $300 \mathrm{ml} \mathrm{min}{ }^{-1}$. The gas mixture was bubbled through water and thus a $90-95 \% \mathrm{RH}$ was maintained in the containers. Gas samples from each container were analyzed daily by gas chromatography. Atmosphere compositions containing 1, 3 or $8 \%$ carbon dioxide (treatments 1,2 and 3, respectively) combined with $21 \%$ oxygen, and compositions containing $0.5,3$ or $8 \%$ carbon dioxide (treatments 4,5 and 6 , respectively) combined with $3 \%$ oxygen, were used while the balance in all treatments was nitrogen. Each gas combination was directed into three containers, each of which served as a replicate. All containers were stored at a temperature of $5^{\circ} \mathrm{C}$. In addition to the above-described six treatments, a sample of 20 fruits was stored at $20^{\circ} \mathrm{C}$ from immediately after harvest, as a control, to follow the normal ripening process of the fruit. Samples of 15 fruits from each replicate of each treatment were transferred periodically to shelf-life conditions in a room at $20^{\circ} \mathrm{C}$ and around $85 \% \mathrm{RH}$, for observation of quality parameters and ripening pattern assessment, after 3, 5, 6, 7 and 9 weeks of CA storage at $5^{\circ} \mathrm{C}$. During shelf-life, firmness measurement and visual assessment of external appearance were performed periodically. 
A Chatillon pressure tester was used to determine firmness of a sample of 5 fruits from each replicate, on two sides of each fruit, during each set of observations. Firmness is presented in newtons $(\mathrm{N})$ required to penetrate unpeeled fruit, using a 6-mm (diameter) conical probe.

Avocado fruit of the 'Hass' cultivar changes colour from green to a characteristic brown-black during normal ripening. For colour assessment four stages were defined: $1=$ green; 2 = changing colour from green to brown; $3=$ most of the peel (exocarp) is brown-black with some green colour; and $4=$ brown-black colour, characteristic of a ripe 'Hass' fruit.

Fruits which became ripe and soft, mostly after 4-5 days in shelf-life conditions, were cut longitudinally into half, and visual assessment of chilling injuries of fruit pulp was carried out according to a four-stage scale of discolouration, where $0=$ no discolouration; 1 = light grey; 2 = intermediate dark-brown discolouration; and 3 = severe dark-brown discolouration. A discolouration index was calculated according to severity of discolouration and number of fruits affected.

At the end of the various storage and shelf-life periods, ripe fruits without pulp discolouration, from all treatments, were tasted by a team of three specialists.

\section{Results}

\section{Firmness}

Firmness of control fruit declined from $140 \mathrm{~N}$ to $14 \mathrm{~N}$ during 8 days at $20^{\circ} \mathrm{C}$. In parallel, they attained the characteristic brown-black colour of a normal ripe 'Hass' fruit, and the pulp was free of injury or discolouration. Fruit of treatment 1 (21\% oxygen and $1 \%$ carbon dioxide) became soft relatively quickly during the first 5 weeks of storage, as their firmness decreased to $30 \mathrm{~N}$, and then leveled off (Fig. 1). The higher the carbon dioxide concentration in the 21\%-oxygen atmosphere, the longer the fruit remained firm during storage at $5^{\circ} \mathrm{C}$. Thus, in an atmosphere containing $8 \%$ carbon dioxide, softening had started only after 7 weeks in storage (Fig. 1, treatment 3). However, when oxygen concentration in the storage atmosphere was reduced to $3 \%$, fruit softening was delayed with all of the carbon dioxide concentrations tested (Fig. 1, treatments 4, 5 and 6). Fruit from all treatments and storage durations, except for fruit of treatment 4, became soft (reached $10 \mathrm{~N}$ ), remained in good quality and was edible 4 days after transfer to shelf-life conditions (data not shown). The fruit of treatment 4 after 9 weeks of storage, did not soften at the same rate. After 2 days in shelf-life conditions following 3,5 or 6 weeks of storage, fruit stored in an atmosphere containing $21 \%$ oxygen in combination with the two lower carbon dioxide concentrations (treatments 1 and 2) became soft more quickly than fruit from treatments 3-6; therefore, these treated fruits started their shelf-life periods at a lower firmness (Fig. 1). It appears that softening rate of fruit in treatments $4-6$ was related to carbon dioxide concentration in the storage atmosphere: the higher the concentration, the slower the softening during shelf-life (data not shown). A similar trend was observed also with treatment 3 as compared with fruit stored in treatments 1 and 2 . As a result of the flow system used, there was no significant accumulation of ethylene in the containers, and thus it 


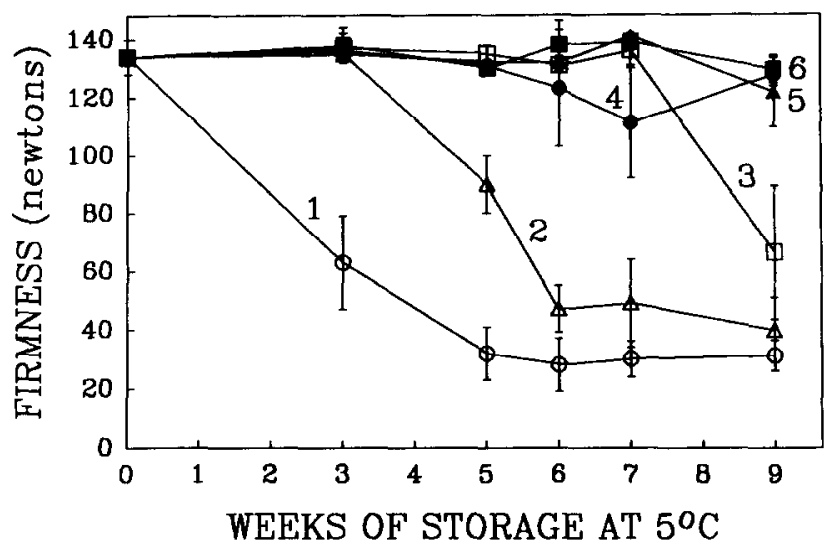

Fig. 1. Firmness of avocado fruit (cv. 'Hass') during storage in different CA conditions for up to 9 weeks at $5^{\circ} \mathrm{C}$. Treatment $1\left(21 \% \mathrm{O}_{2}+1 \% \mathrm{CO}_{2}\right)=0-\mathrm{O}$; treatment $2\left(21 \% \mathrm{O}_{2}+3 \% \mathrm{CO}_{2}\right)=\Delta-\Delta$; treatment $3\left(21 \% \mathrm{O}_{2}+8 \% \mathrm{CO}_{2}\right)=\square-\square$; treatment $4\left(3 \% \mathrm{O}_{2}+0.5 \% \mathrm{CO}_{2}\right)=\bullet-\bullet ;$ treatment 5 $\left(3 \% \mathrm{O}_{2}+3 \% \mathrm{CO}_{2}\right)=\Delta-\Delta ;$ treatment $6\left(3 \% \mathrm{O}_{2}+8 \% \mathrm{CO}_{2}\right)=\square-\mathbf{m}$. In all treatments the balance to $100 \%$ was nitrogen gas. The numbers next to the lines in the figure represent the treatments and the vertical lines represent the standard deviation.

had no significant effect on firmness and other ripening parameters. In treatment 1 , a concentration of $0.3-0.7 \mu \mathrm{l}^{-1}$ ethylene was recorded during storage period while in treatment 2 only $0.2-0.4 \mu \mathrm{l}^{-1}$ and in all other treatments a lower concentration of less than $0.1 \mu 1 \mathrm{l}^{-1}$ ethylene in the atmosphere was measured.

\section{Peel colour}

Fruit stored at $5^{\circ} \mathrm{C}$ in an atmosphere of $21 \%$ oxygen and 1 or $3 \%$ carbon dioxide (treatments 1 and 2) changed colour while in storage; after 3 weeks in storage they had almost reached colour stage 2 (Fig. 2A). Between 5 and 7 weeks of storage, fruit of treatment 1 reached colour stage 4, while the colour change in fruit of treatment 2 was delayed slightly (Fig. 2B-E). In all CA treatments containing $8 \%$ carbon dioxide, or those containing $3 \%$ oxygen in combination with any of the carbon dioxide concentrations tested, there was a distinct retardation of the peel colour development. Fruits in treatments 5 and 6 remained green even after 9 weeks, and those of treatments 3 and 4 started to change their peel colour after 7 and 9 weeks, respectively (Fig. 2D, E).

During the shelf-life period, peel colour of fruit exposed to CA treatments which retarded peel colour development during storage, did change. However, in most of these treatments fruits did not attain the final (stage 4) characteristic colour of ripe fruit and there were obvious green areas on the peels (Fig. 2A-E), even in fruits which had reached eating quality firmness. In CA treatments with low oxygen (treatments 4-6) colour improved at ripening as storage was prolonged, up to 7 weeks of storage; however, after 9 weeks colour development was somewhat retarded (Fig. 2E). 

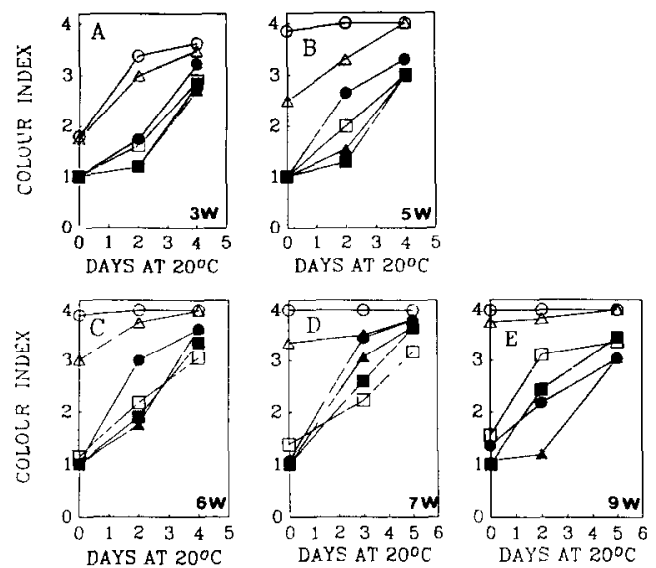

Fig. 2. Peel colour development at shelf-life $\left(20^{\circ} \mathrm{C}\right)$ after different storage durations and CA treatments at $5^{\circ} \mathrm{C}$. The colour index range was defined between 1 and 4 , where 1 represents a green fruit and 4 represents the brown-black colour typical of ripe 'Hass' fruit. The symbols represent the different CA treatments as defined in the legend to Fig. 1.

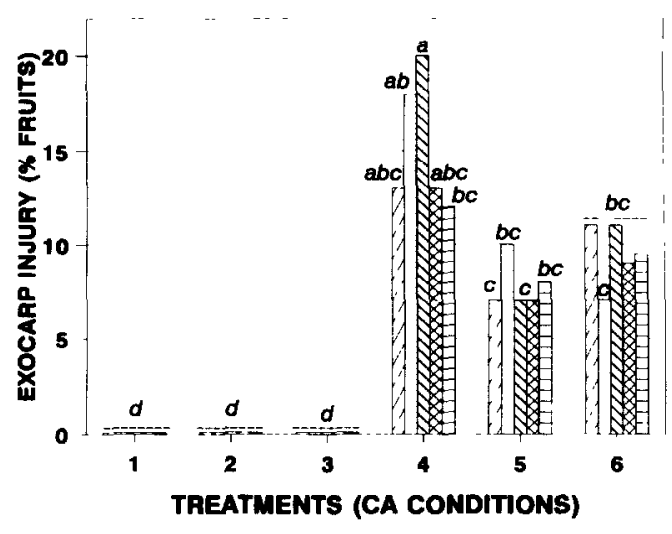

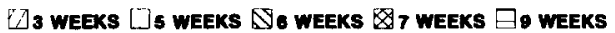

Fig. 3. Peel injuries (damage) of 'Hass' avocado fruit as affected by storage duration under various CA treatments at $5^{\circ} \mathrm{C}$. The data represent (means, $n=3$ ) percentages of fruits with visible damage. The CA treatments are detailed in the legend to Fig. 1. Different letters represent significant differences at $P<0.05$ (Duncan's multiple range comparisons).

\section{Peel injury}

Some peel injury was observed on fruit stored in the low-oxygen atmospheres (Fig. 3, treatments 4-6). At the time of transfer to shelf-life conditions there were brown pitted peel areas of $1-10 \mathrm{~cm}^{2}$, which were quite distinct from the green background colour of the peel. When the fruits ripened, these pitted areas became light brown, against the background of the brown-black characteristic colour of a ripe 'Hass' fruit. When the ripe fruit was peeled, there was poor separation between 


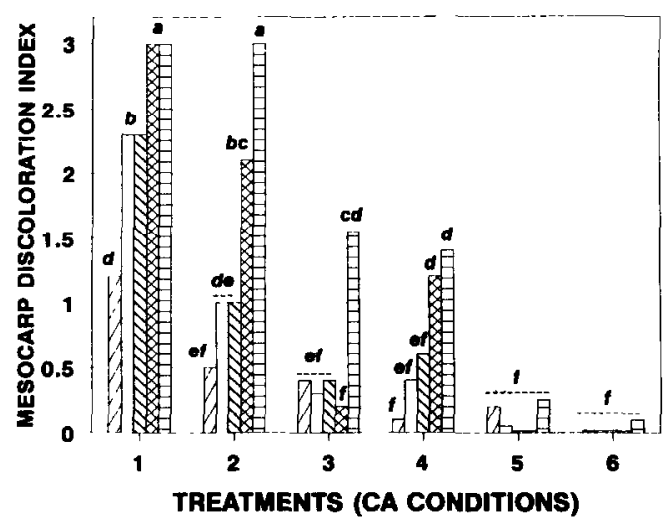

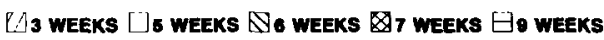

Fig. 4. Chilling injury in 'Hass' avocado fruit as affected by storage duration under different CA treatments at $5^{\circ} \mathrm{C}$. The chilling injury was estimated according to the pulp discolouration index, ranging between 0 (= no discolouration) and 3 (= severe discolouration). CA treatments were as detailed in the legend to Fig. 1. Different letters represent significant differences at $P>0.05$ (Duncan's multiple range comparisons).

the peel and the pulp at the pitted areas; pieces of the pulp under these areas clung to the peel and stayed firm, while the rest of the pulp softened normally. These peel injuries were presented after 3 weeks of storage, but there was no increase in the percentage of injured fruit, nor in the size of the pitted areas on the already injured fruit (Fig. 3). This might indicate that the sensitivity to peel injury is higher during the first 3 weeks of the CA storage. In treatment 4 there were more injured fruits than in the other two treatments which contained the $3 \%$ oxygen concentration (Fig. 3), and the area of injured tissue was larger in treatment 4 than in the other CA treatments (data not shown).

\section{Pulp chilling injury}

Pulp chilling injury was present in fruits of treatment 1 , after 3 weeks at $5^{\circ} \mathrm{C}$ and this increased after 5 and 7 weeks in storage (Fig. 4). Fruits stored in CA treatments with high carbon dioxide and high oxygen (treatment 3 ) and with low oxygen and low carbon dioxide (treatment 4 ), had much less pulp injury even after 9 weeks in storage than fruits stored in treatments 1 and 2 (Fig. 4). Fruits stored in atmospheres containing low oxygen and high carbon dioxide (treatments 5 and 6) had almost no pulp injury even after 9 weeks in storage. In these two treatments, the pulp quality was good when soft, and all fruits tasted by the panel of specialists were edible, with the characteristic taste of the 'Hass' cultivar.

\section{Discussion}

Both increase of carbon dioxide and reduction of oxygen in the storage atmosphere, at $5^{\circ} \mathrm{C}$, favourably affected 'Hass' fruit ripening (softening and peel colour 
change, Figs. 1 and 2), and reduced chilling injury of the peel (Fig. 4). In our study ethylene had no significant effects on fruit quality as the concentrations accumulated in the containers were quite low. In a recent study (Faubion et al., 1992), relative high concentrations of ethylene ( 1 and $10 \mathrm{ppm}$ ) were added continuously through the flow system, which contained only $2.5 \%$ carbon dioxide, and greatly increased softening and chilling injury incidence. A concentration of $8 \%$ carbon dioxide was more effective than one of $3 \%$, in combination with both oxygen concentrations tested; the combination of $3 \%$ oxygen and $8 \%$ carbon dioxide gave the best quality after storage and ripening. This may indicate that there is a synergistic effect between the two gases. The fact that $3 \%$ oxygen was more effective in retarding fruit ripening and chilling injury than $8 \%$ carbon dioxide, suggests that the carbon dioxide concentration could still be increased with improved results. In fact, in many of the studies in which CA storage of avocado has been reported, atmospheres containing $10 \%$ of carbon dioxide were tested (Hatton and Reeder, 1972; Spalding and Reeder, 1975; Barmore and Rouse, 1976; Arpaia et al., 1990; Bower et al., 1990; Truter et al., 1991, 1992; Faubion et al., 1992), however only in one case (Faubion et al., 1992) an advantage of $2.5 \%$ carbon dioxide over $5,7.5$ and $10 \%$ was reported. It appears that peel injury is related to atmospheres containing low oxygen concentrations, since there was no obvious injury in treatments with high oxygen concentrations, and that during the early stages of storage the fruit is more sensitive to peel injury as no additional injury was developed after the third week (Fig. 3).

Results obtained in this study may indicate that CA storage retarded ripening parameters connected with the peel (colour change) more effectively than those connected with the pulp (firmness). In treatments in which softening was retarded for longer times (treatments 4,5 and 6 ) the fruits did not reach their full colour potential, either when they were almost soft (Fig. 2), or when they were completely soft and ready to eat, after 4 days of shelf-life at $20^{\circ} \mathrm{C}$. As shown in previous studies (Fuchs et al., 1986; Zauberman et al., 1988), softening at $20^{\circ} \mathrm{C}$ after prolonged CA storage was quicker (4 days) than softening at $20^{\circ} \mathrm{C}$ immediately after harvest ( 8 days).

The best results in this study, with Israeli grown 'Hass' fruit, were obtained with the combination of $3 \%$ oxygen and $8 \%$ carbon dioxide in the storage atmosphere. Even after 9 weeks of storage fruit had no chilling injury, ripened normally and was edible and marketable. It is suggested that these results might even be improved (yielding storage periods longer than 9 weeks) by using different conditions, such as raising the storage temperature by one or two degrees, in order to reduce chilling injury incidence, and/or by raising the oxygen concentration by 1 or $2 \%$, in order to obtain better colour development during fruit softening.

\section{Acknowledgments}

The authors are thankful to Dr. Sonia Philosoph-Hadas for reading the manuscript and for her helpful suggestions.

Contribution from the Agricultural Research Organization, The Volcani Center, Bet Dagan, Israel. No. 1251-E 1993 series. 


\section{References}

Arpaia, M.L., Faubian, D., Mitchell, F.G. and Mayer, G., 1990. The use of controlled atmosphere for long term storage of 'Hass' avocados. In: J.S. Shepherd (Editor), California Avocado Society 1990 Yearbook. University of California, Altadena, Calif., pp. 43-48.

Barmore, C.R. and Rouse, A.H., 1976. Pectinmethylesterase activity in controlled atmosphere stored avocado. J. Am. Soc. Hortic. Sci., 100: 294-296.

Blanpied, G.D., 1990. Controlled atmosphere storage of apples and pears. In: M. Calderon and R. Barkai-Golan (Editors), Food Preservation by Modified Atmospheres. CRC Press Inc., Boca Raton, Fla., pp. 265-299.

Bower, J.P., Cutting, J.G.M. and Truter, A.B., 1990. Container atmosphere, as influencing some physiological browning mechanisms in stored Fuerte avocados. Acta Hortic., 269: 315-321.

Bramlage, W.J. and Meir, S., 1990. Chilling injury of crops of temperate origin. In: C.Y. Wang (Editor), Chilling Injury of Horticultural Crops. CRC Press Inc., Boca Raton, Fla., pp. 37-49.

Chaplin, G.R., Wills, R.B.H. and Graham, D., 1982. Objective measurement of chilling injury in the mesocarp of stored avocados. HortScience, 17: 238-239.

Faubion, D.F., Mitchell, F.G. and Mayer, G., 1992. Response of Hass avocado to postharvest storage in controlled atmosphere conditions. In: C.J. Lovatt (Editor), Proc. Second World Avocado Congress. University of California, Riverside, Calif., pp. 467-472.

Fuchs, Y., Zauberman, G. and Akerman, M., 1986. Polygalacturonase, cellulase and softening, as related to ethylene production in avocado fruit stored at chilling temperature. Acta Hortic., 179: 801-804.

Golan, A., Kahn, V. and Sadovski, A.Y., 1977. Relationship between polyphenols and browning in avocado mesocarp. Comparison between the 'Fuerte' and 'Lerman' cultivars. J. Agric. Food Chem., 25: $1253-1260$.

Hatton, T.T., Jr. and Reeder, W.F., 1972. Quality of 'Lula' avocados stored in controlled atmospheres with or without ethylene. J. Am. Soc. Hortic. Sci., 97: 339-341.

Hatton, T.T., Jr. and Spalding, D.H., 1990. Controlled atmosphere storage of some tropical fruits. In: M. Calderon and R. Barkai-Golan (Editors), Food Preservation by Modified Atmospheres. CRC Press Inc., Boca Raton, Fla., pp. 301-313.

Kahn, V., 1975. Polyphenol oxidase activity and browning of three avocado varieties. J. Sci. Fond. Agric., 26: 1319-1324.

Resnizky, D. and Sive, A., 1989. CA storage as a solution to a number of problems in the avocado industry. Alon Hanotea, 44: 39-46. (Hebrew with summary in English).

Smock, R.M., 1979. Controlled atmosphere storage of fruits. Hortic. Rev., 1: 301-336.

Spalding, D.H. and Reeder, W.F., 1975. Low-oxygen high-carbon dioxide controlled atmosphere storage for control of anthracnose and chilling injury of avocados. Phytopathology, 65: 458-460.

Truter, A.B., Cutting, J.G.M., Bower, J.P. and Van Eden, S.J., 1991. Effect of modified atmospheres on internal physiological browning of 'Fuerte' avocados. S. Afr. Avocado Grow. Assoc. Yearb., 14: 50-52.

Truter, A.B., Calitz, F.J., Cutting, J.G.M. and Bower, J.P., 1992. Effect of atmosphere modification on internal physiological browning of 'Fuerte' avocados. In: C.J. Lovatt (Editor), Proc. Second World Avocado Congress. University of California, Riverside, Calif., pp. 457-462.

Wang, C.Y., 1990. Physiological and biochemical effect of controlled atmosphere on fruit and vegetables. In: M. Calderon and R. Barkai-Golan (Editors), Food Preservation by Modified Atmospheres. CRC Press Inc., Boca Raton, Fla., pp. 197-223.

Young, R.E., Romani, R.J. and Biale, J.B., 1962. Carbon dioxide effects on fruit respiration, II. Responses of avocado, bananas and lemons to controlled atmospheres. Plant Physiol., 37: 416-422.

Zauberman, G., Fuchs, Y., Yanko, U. and Akerman, M., 1988. Response of mature avocado fruit to postharvest ethylene treatment applied immediately after harvest. HortScience, 23: 588-589. 